\title{
Body composition, bone turnover, and bone mass in trans men during testosterone treatment: 1-year follow-up data from a prospective case-controlled study (ENIGI)
}

\author{
E Van Caenegem ${ }^{1,2}$, K Wierckx ${ }^{1,2}$, Y Taes ${ }^{1}$, T Schreiner ${ }^{2,3}$, S Vandewalle ${ }^{1}, K_{\text {Toye }}{ }^{1}$, \\ B Lapauw', J-M Kaufman' ${ }^{1}$ and G T'Sjoen ${ }^{1,2,4}$ \\ ${ }^{1}$ Department of Endocrinology, Ghent University Hospital, De Pintelaan 185, 9000 Ghent, Belgium, ${ }^{2}$ European \\ Network for the Investigation of Gender Incongruence (ENIGI), Ghent, Belgium, ${ }^{3}$ Department of Endocrinology, \\ Rikshospitalet, Oslo University Hospital, Sognsvannvn 20, Oslo, Norway and ${ }^{4}$ Center for Sexology and Gender \\ Problems, Ghent University Hospital, De Pintelaan 185, Ghent, Belgium
}

\author{
Correspondence \\ should be addressed to \\ E Van Caenegem \\ Email \\ eva.vancaenegem@ugent.be
}

\section{Abstract}

Purpose: To assess the evolution of body composition and bone metabolism in trans men during the first year of cross-sex hormonal therapy.

Methods: In a prospective controlled study, we included 23 trans men (female-to-male trans persons) and 23 age-matched control women. In both groups, we examined grip strength (hand dynamometer), biochemical markers of bone turnover (C-terminal telopeptides of type 1 collagen (CTX) and procollagen 1 aminoterminal propeptide (P1NP)), total body fat and lean mass, and areal bone mineral density (aBMD) by dual-X-ray absorptiometry (DXA) and fat and muscle area at the forearm and calf, bone geometry, and volumetric bone mineral density (vBMD) by peripheral quantitative computed tomography (pQCT), before treatment and after 1 year of treatment with undecanoate (1000 mg i.m./12 weeks). Results: Before hormonal treatment, trans men had similar bone and body composition compared with control women. Testosterone treatment induced in trans men a gain in muscle mass $(+10.4 \%)$ and strength and loss of fat mass $(-9.7 \%)$ (all $P<0.001$ ) and increased the levels of P1NP and CTX (both $P<0.01$ ). Areal and volumetric bone parameters remained largely unchanged apart from a small increase in trabecular VBMD at the distal radius and in BMD at the total hip in trans men ( $P=0.036$ and $P=0.001$ respectively). None of these changes were observed in the control group.

Conclusions: Short-term testosterone treatment in trans men increased muscle mass and bone turnover. The latter may rather reflect an anabolic effect of testosterone treatment rather than bone loss.

\section{Introduction}

The importance of sex steroids in bone health is widely accepted, although the differential effects of estrogen and testosterone individually remain a topic of discussion. In the late 1990s, Riggs et al. (1) described a pivotal role for estrogen in the female and male skeleton. Recent research, assessing bone architecture, has questioned this model. Cortical bone loss still seems related with estrogen deficiency, but trabecular bone loss occurs earlier in adulthood, in both men and women, in the presence of normal sex steroid status, indicative that trabecular bone loss is either (partly) estrogen-independent or requires higher levels for its preservation $(2,3)$. Hence, quantitative computed tomography (QCT) and visualizing bone geometry can contribute for unraveling the interactions of sex steroid with trabecular and cortical bone. Sex steroids also influence bone size: men develop larger 
periosteal (outer) and endosteal (inner) circumference than women, partly due to the interplay of sex steroids, mechanical loading, and the growth hormone (GH)/ insulin-like growth factor 1 (IGF1)-axis during puberty $(4,5,6)$. In adulthood, periosteal apposition continues, but at a slower rate in women than in men (7). Sex steroid reversal, as encountered in trans men on testosterone treatment, may shed light on the role of individual contributions of sex steroids in the sexual dimorphism in bone geometry. Trans men have a female birth sex but identify as, or desire to be, a member of the male gender. In the case of gender dysphoria, this incongruence causes discomfort or distress often leading to the choice for testosterone treatment and/or sex reassignment surgery (SRS, including hysterectomy/salpingo-oophorectomy and mastectomy) (8). We previously reported a substantially higher muscle mass and a larger periosteal and endosteal circumference, higher trabecular volumetric bone mineral density (vBMD) and lower cortical vBMD in a cross-sectional study using peripheral QCT (pQCT) in adult trans men after long-term testosterone treatment (10 years) and SRS compared with age-matched control women (9). This larger bone size was probably mostly explained by the higher androgen-induced muscle mass in trans men $(10,11,12,13)$. In order to explore the direct and indirect (through increased muscle mass) influence of sex steroids on adult bone metabolism, mass, and size, we have set up a prospective controlled study in trans men, before any hormonal treatment compared with agematched healthy control women. We evaluated body composition, bone turnover, volumetric (using pQCT), and areal bone parameters (using dual-X-ray absorptiometry (DXA)) in control women and trans men before and after the first year of testosterone therapy.

\section{Subjects and methods}

\section{Study design and population}

All trans men were diagnosed with gender dysphoria (DSM-5, 302.85; ICD-10, F64.0) and were recruited from the Center for Sexology and Gender Problems at the Ghent University Hospital, Belgium. All were treated following the World Professional Association for Transgender Health standards of care (8). This research is part of the 'European Network for the Investigation of Gender Incongruence' (ENIGI), a collaboration of four major West European gender identity clinics (Amsterdam, Ghent, Hamburg, and Oslo), a study group created to obtain more transparency in diagnostics and treatment of gender dysphoria (14).
Between February 2010 and October 2012, 30 trans men were included in the study. After screening by thorough medical history and determination of serum sex steroids, seven of them were excluded because of: past or present use of androgens substitution therapy $(n=2)$, anorexia nervosa in the past $(n=2)$, cerebral palsy $(n=1)$, refusal of bone densitometry $(n=1)$, and other treatment protocol $(n=1)$. In total, 23 trans men who had never used any kind of cross-sex hormonal treatment and, thus before SRS, were included. All participants were Caucasian. A female control population was recruited $(n=23)$, matched for age $( \pm 2$ years, median 1 year). These were women responded on posters spread at the Ghent University sites, Ghent University Hospital, and on its website.

All participants were in good physical health and completed questionnaires about previous illness and medication use, current and past smoking habits, and physical activity by recording the weekly frequency of sports, recreational, and/or working activities (using Baecke's questionnaire (15)). Gynecological history was obtained in both trans men and control women and history of menstrual irregularities, hirsutism, or polycystic ovarian syndrome (PCOS) and the use of oral contraceptives (at baseline) were additional exclusion criteria for control women. Two trans men had a history of PCOS. Nine trans men used progestagens at baseline. The trans men and control women were evaluated after 1 year. In trans men, structured clinical visits were conducted at 3, 6, and 9 months. Trans men who used progestagens before the baseline study visit had similar baseline bone turnover, bone parameters, and body composition compared with trans men who did not (data not shown).

This data are part of a large prospective study (ENIGI), at the time of this analysis, 23 trans men had completed the 1-year follow-up. Three control women were no longer interested and did not complete the 1-year follow-up. All trans men received injections with i.m. testosterone undecanoate of $1000 \mathrm{mg}$ (Nebido; Bayer), sometimes preceded by progestagens to suppress the menstrual cycle. Injections were administered at baseline, after 6 and 18 weeks, and from then once every 12 weeks. In case of nontolerance, injections with i.m. testosterone esters, every 2 weeks (testosterone decanoate $100 \mathrm{mg}$, testosterone isocaproate $60 \mathrm{mg}$, testosterone fenylpropionate $60 \mathrm{mg}$, and testosterone propionate $30 \mathrm{mg} / \mathrm{ml}$ ) (Sustanon 250; Aspen, Dublin, Ireland) were prescribed $(n=1)$. Nine trans men had undergone SRS before the study visit at year 1 . The changes in body composition, markers of bone turnover, and bone parameters were similar in trans men 
who underwent SRS during the first year of follow-up and those who did not (data not shown).

None of the subjects used vitamin D or calcium supplements or bone-active drugs (e.g. bisphosphonates) before the first study visit. In trans men with vitamin D insufficiency $(<20 \mathrm{ng} / \mathrm{ml} ; n=9)$, vitamin $\mathrm{D}$ supplements were prescribed. At year 1, only two subjects still used the vitamin D supplements. The study protocol was approved by the ethics review board of the Ghent University Hospital, registered with clinicaltrials.gov (identifier: NCT01072825), and all participants gave written informed consent.

\section{Biochemical determinations}

Venous blood samples were obtained between 0800 and $1000 \mathrm{~h}$ after overnight fasting. All samples were stored at $-80{ }^{\circ} \mathrm{C}$ until analysis.

Testosterone and estradiol $\left(\mathrm{E}_{2}\right)$ were determined by liquid chromatrography-mass spectrometry (LCMS/MS) on an $\mathrm{AB}$ Sciex 5500 triple-quadrupole mass spectrometer (AB Sciex, Toronto, ON, Canada) (16). Commercial immunoassays were used to determine the serum concentrations of luteinizing hormone (LH), follicle-stimulating hormone (FSH), 25-hydroxyvitamin D $(25(\mathrm{OH}) \mathrm{D})$, parathyroid hormone (PTH), C-terminal telopeptides of type 1 collagen (CTX) (bone resorption) (Modular, Roche Diagnostics), procollagen 1 aminoterminal propeptide (P1NP) (bone formation) (Cobas 411, Roche Diagnostics), and IGF1 (Cisbio bioassays, Codolet, France). The intra assay coefficients and interassay coefficients of variation (CV) for all assays were $<10 \%$.

\section{Body composition, muscle strength, and areal bone mineral density}

Body weight and anthropometrics were measured in light indoor clothing without shoes. Standing height was measured using a wall-mounted Harpenden stadiometer (Holtain, Ltd, Crymuch, UK). The waist circumference was defined as the abdominal circumference located in the middle between the lower rib and the iliac crest and the hip circumference as the widest circumference around the buttocks.

Grip strength at the dominant hand was measured using an adjustable hand-held standard grip device (JAMAR hand dynamometer, Sammons and Preston, Bolingbrook, IL, USA). A maximum strength of three attempts was assumed to best reflect the current status and history of their musculoskeletal adaptation and was expressed in kilograms.
Body fat and lean mass, bone mineral content (BMC), projected bone area and areal bone mineral density (aBMD) at the whole body, lumbar spine, nondominant forearm, and left proximal femur (total hip and femoral neck region) were measured by DXA using a Hologic Discovery device (Software Version 11.2.1, Hologic, Inc., Bedford, MA, USA). The CV for both spine and whole-body calibration phantoms was $<1 \%$, as calculated from daily and weekly measurements respectively.

\section{Volumetric bone parameters and cross-sectional muscle and fat area}

A pQCT device (XCT-2000, Stratec Medizintechnik, Pforzheim, Germany) was used to evaluate the cortical vBMD and bone geometry at the dominant midshaft radius and tibia (at $66 \%$ of bone length) and trabecular vBMD at the metaphysis (at $4 \%$ of bone length) of the distal radius at the dominant side and cross-sectional muscle and fat area (at $66 \%$ of bone length). The details of procedure were as described previously (17). Scannings with large movement artifacts (distal radius: $n=1$, midshaft radius: $n=3$, and midshaft tibia: 3 ) and suspected position error ( $>10 \%$ variation of total bone area at distal radius: $n=3$, midshaft radius: $n=9$, and midshaft tibia: $n=2$ ) were excluded.

\section{Statistical analyses}

Descriptives were expressed as mean and S.D. or median (1st-3rd quartile) when criteria for normal distribution were not fulfilled. Comparison of general, anthropometric, biochemical, and hormonal determinations between trans men and age-matched controls were made using an independent sample $t$-test (or Mann-Whitney $U$ test, when criteria for normal distribution were not fulfilled). In order to adjust for height, multiple regression analysis was used to compare bone and body composition in trans men compared with control women at baseline. The models included height and treatment group (trans men or control women) as independent variables. The $P$ value of this grouping variable (baseline comparison) is given in Tables 1, 2, 3 and 4 .

Repeated measurements before and after 1 year were analyzed using models for repeated measures with treatment group and time of visit (baseline or 12 months) as a fixed variables (and height as covariate for bone and body composition parameters). The $P$ value of the interaction term of treatment group with visit is shown (comparison over time). $P$ values $<0.05$ were considered 
Table 1 General characteristics, hormones, and bone turnover markers in control women and trans men before and after 12 months. Descriptives are expressed as mean \pm s.D. or as median (1st-3rd quartile) when not normally distributed.

\begin{tabular}{|c|c|c|c|c|c|c|c|c|}
\hline & \multicolumn{3}{|c|}{ Baseline } & \multicolumn{2}{|c|}{12 months } & \multicolumn{3}{|c|}{$\begin{array}{l}\text { Paired difference baseline-12 } \\
\text { months }(\%)\end{array}$} \\
\hline & $\begin{array}{l}\text { Control } \\
\text { women } \\
(n=23)\end{array}$ & $\begin{array}{l}\text { Trans men } \\
(n=23)\end{array}$ & $\begin{array}{l}\text { Baseline } \\
\text { comparison }\end{array}$ & $\begin{array}{l}\text { Control } \\
\text { women } \\
(n=20)\end{array}$ & $\begin{array}{l}\text { Trans men } \\
(n=23)\end{array}$ & $\begin{array}{l}\text { Control } \\
\text { women } \\
(n=20)\end{array}$ & $\begin{array}{c}\text { Trans } \\
\text { men } \\
(n=23)\end{array}$ & $\begin{array}{l}\text { Comparison } \\
\text { over time: } \\
\text { time } \times \text { group }\end{array}$ \\
\hline Age (years) & $27 \pm 9$ & $27 \pm 9$ & & & & & & \\
\hline Pack year & $0(0-0)$ & $0(3-4)$ & $\dagger$ & & & & & \\
\hline Weight (kg) & $66.8 \pm 7.7$ & $65.5 \pm 14.5$ & & $68.3 \pm 9.1$ & $67.4 \pm 11.6$ & 1.6 & 3.6 & \\
\hline Height $(\mathrm{cm})$ & $168.5 \pm 5.7$ & $163.3 \pm 4.3$ & ††† & & & & & \\
\hline Fracture prevalence $(\%)^{a}$ & 35 & $2 \overline{0}$ & & & & & & \\
\hline Parity $(\%)^{a}$ & 30 & 17 & $\dagger$ & & & & & \\
\hline Sport index ${ }^{b}$ & $2.9 \pm 1.0$ & $3.3 \pm 1.5$ & & $2.4 \pm 1.0$ & $3.6 \pm 1.7$ & -8.6 & 11.7 & \\
\hline Leisure time index ${ }^{b}$ & $3.3 \pm 0.7$ & $2.6 \pm 0.8$ & $\dagger$ & $3.3 \pm 0.6$ & $2.8 \pm 0.8$ & 4.0 & 7.6 & \\
\hline Work index ${ }^{\mathrm{b}}$ & $2.3 \pm 0.6$ & $2.9 \pm 0.7$ & $\dagger$ & $2.4 \pm 0.5$ & $3.0 \pm 0.8$ & 9.8 & 5.2 & \\
\hline Total physical activity ${ }^{\mathrm{b}}$ & $8.5 \pm 1.5$ & $8.9 \pm 2.2$ & & $8.0 \pm 1.6$ & $9.3 \pm 2.5$ & -1.8 & 6.2 & \\
\hline Testosterone (ng/dl) & $31 \pm 12$ & $27 \pm 12$ & & $29 \pm 8$ & $629 \pm 225$ & 2.5 & 2732.2 & *** \\
\hline $\mathrm{E}_{2}(\mathrm{pg} / \mathrm{ml})$ & $57(43-124)$ & $54(24-110)$ & & $99(39-158)$ & $31(23-36)$ & 62.9 & -8.0 & *** \\
\hline $\mathrm{LH}(\mathrm{U} / \mathrm{l})^{\mathrm{c}}$ & $8(5-14)$ & $5(4-8)$ & $\dagger$ & $7(6-9)$ & $2(0-5)$ & 3.3 & -11.0 & \\
\hline FSH $(U / I)^{d}$ & $7(5-8)$ & $4(3-8)$ & & $5(4-6)$ & $5(1-7)$ & -11.7 & 53.8 & \\
\hline $25-\mathrm{OH}$ vitamin D (ng/ml) & $25 \pm 12$ & $19 \pm 11$ & & $28 \pm 14$ & $22 \pm 12$ & 22.1 & 14.1 & \\
\hline P1NP $(\mu g / l)$ & $63 \pm 36$ & $62 \pm 34$ & & $59 \pm 31$ & $102 \pm 63$ & -2.9 & 67.7 & *** \\
\hline CTX (ng/ml) & $\begin{array}{c}0 . \overline{46} \\
(0.33-0.68)\end{array}$ & $\begin{array}{c}0 . \overline{38} \\
(0.27-0.65)\end{array}$ & & $\begin{array}{c}0.44 \\
(0.38-0.56)\end{array}$ & $\begin{array}{c}0.48 \\
(0.38-0.65)\end{array}$ & 1.2 & 27.0 & $\star *$ \\
\hline
\end{tabular}

Baseline comparison: all variables were adjusted for height. ${ }^{a}$ Using $\chi^{2}$-test, ${ }^{b}$ following Baecke et al. 1982 (15), ${ }^{c}$ detection limit LH-assay $=0.1 \mathrm{U} / \mathrm{l}$, ${ }^{\mathrm{d}}$ detection limit $\mathrm{FSH}$-assay $=0.1 \mathrm{U} / \mathrm{l}$. Parity: \% of participants who gave birth. The baseline comparison (third column) is adjusted for height, the $P$ value for the group (control women or trans man) is given by ${ }^{\dagger} P<0.05,{ }^{+\dagger} P \leq 0.001$. The comparison over time (last column) is performed by an ANOVA for repeated measurements with group (trans men or control women), visit (baseline or 12 months), and height as independents: $P$ value for visit $\times$ group, $* * P<0.01$, and $* * * P \leq 0.001$.

to be statistically significant, all tests were two-tailed. Data were analyzed using SPSS Software, version 21 (SPSS, Inc.).

\section{Results}

\section{Baseline comparison}

Trans men and control women had a median age of 27 years (range 18-47 years; Table 1). Both groups had comparable weight and BMI, though trans men had shorter stature than control women. The group of trans men comprised more active and smokers $26 \%$ vs $9 \%$ and more ex-smokers $35 \%$ vs $14 \%$ (Fisher's exact test: $P=0.038$ ) and the amount of pack years was higher. Total testosterone and $\mathrm{E}_{2}$ were comparable in both groups. LH was slightly lower in trans men (range 1-31) compared with (range 1-50) control women (Table 1).

Trans men and control women had similar measures of fat and muscle mass and strength (Table 2). Waist-to-hip ratio was significantly higher in trans men, possibly due to a lower hip circumference.

Areal BMD (Table 3), trabecular and cortical vBMD, cortical bone size (Table 4), and bone turnover markers (Table 1) were comparable in trans men and control women at baseline; however, trabecular vBMD at the radius seemed slightly higher in trans men (nonsignificant).

\section{Follow-up after 1-year of testosterone therapy}

In trans men, serum testosterone increased and $\mathrm{E}_{2}$ levels decreased significantly and both were within the normal male ranges at year 1 (Table 1). We observed a $10.4 \%$ increase in lean body mass and $9.7 \%$ decrease in total body fat mass during the first year of testosterone treatment in trans men (vs +0.7 and $+5.9 \%$ in control women during 1 year follow-up) in the presence of unchanged BMI and waist and hip circumference. Similar trends were observed at the peripheral limbs and this increase in muscle mass was reflected by a higher grip strength after testosterone treatment $(+18.2 \%)$. Other changes in body composition is given in Table 2 .

Markers of bone formation, especially P1NP, markedly increased during the first year of treatment in trans men, whereas no changes over time were noted in control women (Table 1).

Short-term evaluation of areal and volumetric parameters showed a largely unchanged status apart from a 
Table 2 Body composition in control women and trans men before and after 12 months. Descriptives are expressed as mean \pm s.D. or as median (1st-3rd quartile) when not normally distributed.

\begin{tabular}{|c|c|c|c|c|c|c|c|c|}
\hline & \multicolumn{3}{|c|}{ Baseline } & \multicolumn{2}{|c|}{12 months } & \multicolumn{3}{|c|}{$\begin{array}{c}\text { Paired difference baseline-12 } \\
\text { months (\%) }\end{array}$} \\
\hline & $\begin{array}{l}\text { Control } \\
\text { women } \\
(n=23)\end{array}$ & $\begin{array}{l}\text { Trans men } \\
(n=23)\end{array}$ & $\begin{array}{l}\text { Baseline } \\
\text { comparison }\end{array}$ & $\begin{array}{l}\text { Control } \\
\text { women } \\
(n=20)\end{array}$ & $\begin{array}{l}\text { Trans men } \\
(n=23)\end{array}$ & $\begin{array}{l}\text { Control } \\
\text { women } \\
(n=20)\end{array}$ & $\begin{array}{l}\text { Trans men } \\
(n=23)\end{array}$ & $\begin{array}{l}\text { Comparison } \\
\text { over time: } \\
\text { time } \times \text { group }\end{array}$ \\
\hline BMI $\left(\mathrm{kg} / \mathrm{m}^{2}\right)$ & $23.7 \pm 3.0$ & $24.5 \pm 5.3$ & & $24.1 \pm 3.5$ & $25.2 \pm 4.1$ & 2.1 & 3.9 & \\
\hline Waist circumference $(\mathrm{cm})$ & $72.2 \pm 6.5$ & $78.4 \pm 14.2$ & & $74.0 \pm 10.0$ & $78.2 \pm 11.3$ & 2.6 & 0.5 & \\
\hline Hip circumference $(\mathrm{cm})$ & $100.3 \pm 7.0$ & $99.1 \pm 7.9$ & & $99.3 \pm 9.1$ & $98.4 \pm 7.4$ & -0.9 & -0.5 & \\
\hline Waist-to-hip ratio & $0.7 \pm 0.0$ & $0.8 \pm 0.1$ & $\dagger$ & $0.8 \pm 0.1$ & $0.8 \pm 0.1$ & 4.5 & 1.1 & \\
\hline Total body - fat mass $(\mathrm{kg})$ & $19.3 \pm 6.1$ & $19.9 \pm 8.7$ & & $20.0 \pm 7.3$ & $17.5 \pm 6.7$ & 5.9 & -9.7 & $* * *$ \\
\hline Total body - fat mass (\%) & $28 \pm 6$ & $29 \pm 7$ & & $29 \pm 7$ & $25 \pm 6$ & 3.4 & -13.6 & $* * *$ \\
\hline Trunk fat mass (kg) & $7.3(4.7-11.0)$ & $6.5(5.2-10.7)$ & & $6.4(4.7-10.7)$ & $6.5(4.5-9.9)$ & 6.8 & -4.4 & *** \\
\hline Fat CSA forearm $\left(\mathrm{cm}^{2}\right)$ & $13(10-14)$ & $12(9-17)$ & & $14(11-15)$ & $11(8-15)$ & 2.5 & -10.8 & \\
\hline Fat CSA calf $\left(\mathrm{cm}^{2}\right)$ & $28(23-30)$ & $29(22-34)$ & & $28(22-33)$ & $25(19-29)$ & 1.6 & -12.9 & ** \\
\hline Total body - lean mass $(\mathrm{kg})$ & $45.4 \pm 3.1$ & $43.5 \pm 6.9$ & & $46 \pm 4.1$ & $47.7 \pm 6.1$ & 0.7 & 10.4 & $* * *$ \\
\hline Total body - lean mass (\%) & $68 \pm 6$ & $67 \pm 6$ & & $68 \pm 7$ & $72 \pm 6$ & -1.3 & 6.5 & $* * *$ \\
\hline Grip strength (N/kg) & $32 \pm 4$ & $30 \pm 6$ & & $31 \pm 4$ & $35 \pm 5$ & -1.2 & 18.2 & $* * *$ \\
\hline Muscle CSA forearm $\left(\mathrm{cm}^{2}\right)$ & $28 \pm 3$ & $29 \pm 5$ & & $28 \pm 3$ & $34 \pm 5$ & 0.2 & 16.6 & $* * *$ \\
\hline Muscle CSA calf $\left(\mathrm{cm}^{2}\right)$ & $68 \pm 8$ & $64 \pm 12$ & & $70 \pm 8$ & $73 \pm 13$ & 1.2 & 13.6 & $* * *$ \\
\hline
\end{tabular}

CSA, cross-sectional area. Baseline comparison: all variables were adjusted for height. The baseline comparison (third column) is adjusted for height, the $P$ value for the group (control women or trans man) is given by ${ }^{\dagger} P<0.05$. The comparison over time (last column) is performed by an ANOVA for repeated measurements with group (trans men or control women), visit (baseline or 12 months) and height as independents: $P$ value for visit $\times$ group, $* * P<0.01$, and $* * * P \leq 0.001$.

modest gain of aBMD at the total hip and of trabecular vBMD at the distal radius in trans men (Table 3 ). No changes were recorded in cortical vBMD or bone size over time and/or between groups (Table 4).

\section{Discussion}

In this prospective controlled study, we showed that testosterone therapy in trans men induced changes in body composition including a gain in lean body mass, muscle mass, and strength. Bone turnover markers increased significantly during the first year of testosterone treatment in trans men.

The increased muscle mass and loss of fat mass are consistent with previous research carried out in trans men using testosterone treatment $(10,11,12,13)$ and confirm the anabolic effects of testosterone on skeletal muscle described in men (18).

A rise in bone formation marker in trans men has been reported during the first 2 years of testosterone treatment $(11,19)$ and higher bone formation markers were observed in trans men after long-term testosterone treatment vs control women (9). The latter long-term study also demonstrated higher serum levels of bone resorption markers, which is in agreement with the current results (9). However, not all studies in trans men documented higher bone resorption $(11,19,20)$. Furthermore, our observations on areal bone parameters correspond with previous research reporting a preservation of aBMD during the first years of testosterone treatment $(11,12,13,21,22)$ as well as after a longer exposure time and SRS (up to 10 years) in trans men $(19,20,23)$. Some studies even reported a higher aBMD at cortical sites (femoral neck $(9,21)$, wholebody and tibial diaphysis (20)) and cortical thickness (iliac crest (24)) as well as greater bone size (larger periosteal and endosteal circumference of the radius) (9) in trans men compared with control women. The currently observed modest rise in aBMD at the total hip in a short-term may be in line with these results. Though the current bone data may be preliminary, the small gain in trabecular vBMD confirms our earlier cross-sectional research showing higher values in trans men on long-term testosterone treatment compared with control women (9).

We hypothesize that the increased bone turnover and discrete increases in aBMD at the total hip and trabecular vBMD may be due to the indirect effects of testosterone therapy. Following the mechanostat theory, the considerable increase in muscle mass imposes a higher strain on bone which stimulates higher bone modeling and remodeling (25). Indeed, muscle mass constitutes one of the main triggers in periosteal bone formation during puberty $(6,25,26)$, and a beneficial effect of structured exercise in premenopausal women on femoral neck and lumbar spine aBMD was demonstrated in a recent 
Table 3 Areal bone parameters in control men and trans men before and after 12 months. Descriptives are expressed as mean \pm s.D. or as median (1st-3rd quartile) when not normally distributed.

\begin{tabular}{|c|c|c|c|c|c|c|c|c|}
\hline & \multicolumn{3}{|c|}{ Baseline } & \multicolumn{2}{|c|}{12 months } & \multicolumn{3}{|c|}{$\begin{array}{l}\text { Paired difference baseline-12 } \\
\text { months }(\%)\end{array}$} \\
\hline & $\begin{array}{l}\text { Control } \\
\text { women } \\
(n=23)\end{array}$ & $\begin{array}{l}\text { Trans men } \\
(n=23)\end{array}$ & $\begin{array}{l}\text { Baseline } \\
\text { comparison }\end{array}$ & $\begin{array}{l}\text { Control } \\
\text { women } \\
(n=20)\end{array}$ & $\begin{array}{l}\text { Trans men } \\
(n=23)\end{array}$ & $\begin{array}{l}\text { Control } \\
\text { women } \\
(n=20)\end{array}$ & $\begin{array}{c}\text { Trans } \\
\text { men } \\
(n=23)\end{array}$ & $\begin{array}{c}\text { Comparison } \\
\text { over time: } \\
\text { time } \times \text { group }\end{array}$ \\
\hline \multicolumn{9}{|l|}{ Lumbar spine } \\
\hline Bone area $\left(\mathrm{cm}^{2}\right)$ & $59.2 \pm 6.7$ & $56.7 \pm 5.1$ & & $59.8 \pm 7.1$ & $56.6 \pm 4.6$ & 0.3 & -0.1 & \\
\hline BMC (g) & $59.5 \pm 9.9$ & $58.4 \pm 7.6$ & & $59.8 \pm 10.1$ & $58.3 \pm 6.9$ & -0.2 & -0.1 & \\
\hline $\mathrm{aBMD}\left(\mathrm{g} / \mathrm{cm}^{2}\right)$ & $1.008 \pm 0.150$ & $1.029 \pm 0.085$ & & $1.005 \pm 0.126$ & $1.029 \pm 0.084$ & -0.5 & 0.0 & \\
\hline \multicolumn{9}{|l|}{ Femoral neck } \\
\hline Bone area $\left(\mathrm{cm}^{2}\right)$ & $4.9 \pm 0.2$ & $4.9 \pm 0.3$ & & $5.0 \pm 0.3$ & $4.9 \pm 0.3$ & 1.9 & 0.2 & \\
\hline BMC (g) & $4.3 \pm 0.7$ & $4.2 \pm 0.5$ & & $4.4 \pm 0.7$ & $4.2 \pm 0.5$ & 0.7 & 0.1 & \\
\hline aBMD $\left(\mathrm{g} / \mathrm{cm}^{2}\right)$ & $0.877 \pm 0.142$ & $0.861 \pm 0.101$ & & $0.879 \pm 0.143$ & $0.862 \pm 0.102$ & -1.2 & 0.2 & \\
\hline \multicolumn{9}{|l|}{ Total hip } \\
\hline Bone area $\left(\mathrm{cm}^{2}\right)$ & $32.8 \pm 2.7$ & $33.7 \pm 2.7$ & $\dagger$ & $32.8 \pm 2.9$ & $33.6 \pm 2.8$ & 0.0 & -0.2 & \\
\hline BMC (g) & $31.4 \pm 5.3$ & $32.6 \pm 4.3$ & & $31.5 \pm 5.3$ & $33.1 \pm 4.5$ & -0.5 & 1.3 & $\star *$ \\
\hline aBMD $\left(\mathrm{g} / \mathrm{cm}^{2}\right)$ & $0.958 \pm 0.146$ & $0.971 \pm 0.112$ & & $0.963 \pm 0.150$ & $0.985 \pm 0.112$ & -0.6 & 1.5 & $* * *$ \\
\hline \multicolumn{9}{|l|}{ Total body } \\
\hline Bone area $\left(\mathrm{cm}^{2}\right)$ & $2050.6 \pm 118.7$ & $1970.5 \pm 134.4$ & & $2061.2 \pm 115.0$ & $1967.1 \pm 138.2$ & 0.0 & -0.2 & \\
\hline BMC (g) & $2208.6 \pm 267.4$ & $2156.0 \pm 222.2$ & & $2238.3 \pm 275.2$ & $2163.7 \pm 217.8$ & 0.3 & 0.4 & \\
\hline aBMD $\left(\mathrm{g} / \mathrm{cm}^{2}\right)$ & $1.076 \pm 0.104$ & $1.093 \pm 0.068$ & & $1.085 \pm 0.110$ & $1.099 \pm 0.064$ & 0.3 & 0.6 & \\
\hline \multicolumn{9}{|l|}{ Radius } \\
\hline Bone area $\left(\mathrm{cm}^{2}\right)$ & $13.5 \pm 0.9$ & $13.3 \pm 1.2$ & & $13.6 \pm 1$ & $13.4 \pm 1.2$ & 1.9 & 0.7 & \\
\hline BMC (g) & $7.8 \pm 0.7$ & $7.5 \pm 0.9$ & & $7.9 \pm 0.8$ & $7.4 \pm 0.9$ & 1.6 & -0.3 & \\
\hline aBMD $\left(\mathrm{g} / \mathrm{cm}^{2}\right)$ & $0.582 \pm 0.046$ & $0.559 \pm 0.041$ & & $0.583 \pm 0.047$ & $0.555 \pm 0.039$ & -0.3 & -1.0 & \\
\hline
\end{tabular}

Baseline comparison: all variables were adjusted for height. The baseline comparison (third column) is adjusted for height, the $P$ value for the group (control women or trans man) is given by ${ }^{\dagger} P<0.05$. The comparison over time (last column) is performed by an ANOVA for repeated measurements with group (trans men or control women), visit (baseline or 12 months) and height as independents: $P$ value for visit $\times$ group, $* \star P<0.01$, and $* \star \star P \leq 0.001$.

meta-analysis (27). In some of these trials, the training indeed promoted bone formation (28). A second indirect action of testosterone can be through the aromatization in estrogens. Estrogens also affect bone size and may interact with mechanical loading (6).

The anabolic effect of testosterone on female body composition and bone metabolism is further supported by research in women with endogenous hyperandrogenism and postmenopausal women on testosterone therapy. A higher regional muscle mass (29), higher trabecular vBMD $(30,31)$, and aBMD at the lumbar spine $(32,33)$ as well as larger cortical bone size (31) and aBMD at cortical sites (whole body $(32,34)$ and femoral neck (33)) were described in women with endogenous hyperandrogenism and/or hirsutism. Similarly, exogenous testosterone added to hormonal replacement therapy in postmenopausal women resulted in higher lean body mass and muscle mass $(35,36)$ and increased hip $(35,37)$ and spine aBMD $(35,38)$ after 2 years compared with estrogen treatment alone.

Furthermore, higher muscle mass and strength have indeed been positively associated with trabecular vBMD in women $(39,40,41)$ and a higher trabecular number and/or thickness have been related with higher appendicular muscle mass in women (41). Men develop thicker trabeculae during puberty $(3,4,42)$ and we might presume that testosterone treatment in trans men led to the acquisition of thicker trabeculae and consequently higher measured trabecular vBMD similar to that young males compared with females. High resolution pQCT and longer follow-up are however needed to explore the trabecular microarchitecture of trans men. Furthermore, the trabecular vBMD seemed higher in trans men before treatment, compared control women, therefore baseline differences cannot be ruled out. Trans men might have participated more in sports during puberty, leading to higher trabecular vBMD (43).

In addition to effects on BMD, sex steroid exposure appears to affect bone size (6). During puberty, men develop larger bone size partly due to the interplay of sex steroids with mechanical loading $(6,44)$, and positive relationships of testosterone with periosteal circumference have been observed in pubertal boys and young men $(5,6$, 45). The current results cannot confirm the previously reported larger radial cortical bone size and thinner cortex in trans men after 10 year of testosterone treatment compared with control women (9), although the observation time was probably too short to detect changes. 
Table 4 Volumetric bone parameters at the radius and tibia in control women and trans men before and after 12 months. Descriptives are expressed as mean \pm s.D. or as median (1st-3rd quartile) when not normally distributed.

\begin{tabular}{|c|c|c|c|c|c|c|c|c|}
\hline & \multicolumn{3}{|c|}{ Baseline } & \multicolumn{2}{|c|}{12 months } & \multicolumn{3}{|c|}{$\begin{array}{c}\text { Paired difference baseline-12 } \\
\text { months }(\%)\end{array}$} \\
\hline & $\begin{array}{l}\text { Control } \\
\text { women } \\
(n=23)\end{array}$ & $\begin{array}{c}\text { Trans men } \\
(n=23)\end{array}$ & $\begin{array}{l}\text { Baseline } \\
\text { comparison }\end{array}$ & $\begin{array}{l}\text { Control } \\
\text { women } \\
(n=20)\end{array}$ & $\begin{array}{c}\text { Trans men } \\
(n=23)\end{array}$ & $\begin{array}{l}\text { Control } \\
\text { women } \\
(n=20)\end{array}$ & $\begin{array}{l}\text { Trans } \\
\text { men } \\
(n=23)\end{array}$ & $\begin{array}{c}\text { Comparison } \\
\text { over time: } \\
\text { time } \times \text { group }\end{array}$ \\
\hline Trabcular vBMD $\left(\mathrm{mg} / \mathrm{cm}^{3}\right)$ & $189 \pm 46$ & $205 \pm 42$ & NS & $193 \pm 50$ & $208 \pm 42$ & 0.5 & 1.1 & * \\
\hline Trabecular bone area $\left(\mathrm{mm}^{2}\right)$ & $148.7 \pm 18.8$ & $148.1 \pm 16.9$ & NS & $149.2 \pm 19.8$ & $148.2 \pm 17.2$ & 0.4 & 0.5 & \\
\hline Cortical vBMD $\left(\mathrm{mg} / \mathrm{cm}^{3}\right)$ & $1113 \pm 21$ & $1116 \pm 30$ & NS & $1120 \pm 28$ & $1113 \pm 30$ & 0.4 & -0.1 & \\
\hline Cortical bone area $\left(\mathrm{mm}^{2}\right)$ & $77.1 \pm 10.2$ & $78.2 \pm 9$ & NS & $77.2 \pm 9.8$ & $80.1 \pm 9.4$ & 0.1 & 0.4 & \\
\hline Cortical thickness (mm) & $2.1 \pm 0.2$ & $2.2 \pm 0.2$ & NS & $2.1 \pm 0.3$ & $2.2 \pm 0.3$ & 0.8 & 0.1 & \\
\hline Periostal circumference (mm) & $43 \pm 3$ & $43 \pm 3$ & NS & $43 \pm 3$ & $43 \pm 3$ & -0.3 & -0.2 & \\
\hline Endosteal circumference (mm) & $30 \pm 3$ & $29 \pm 3$ & NS & $29 \pm 4$ & $29 \pm 3$ & -0.8 & -2.1 & \\
\hline \multicolumn{9}{|l|}{ Tibia } \\
\hline Cortical vBMD $\left(\mathrm{mg} / \mathrm{cm}^{3}\right)$ & $1116 \pm 25$ & $1125 \pm 22$ & NS & $1122 \pm 22$ & $1125 \pm 17$ & 0.6 & -0.2 & \\
\hline Cortical bone area $\left(\mathrm{mm}^{2}\right)$ & $285.0 \pm 31.8$ & $283.0 \pm 28.0$ & NS & $287.7 \pm 32.1$ & $283.3 \pm 31.2$ & 0.9 & 0.6 & \\
\hline Cortical thickness (mm) & $3.8 \pm 0.5$ & $3.9 \pm 0.3$ & NS & $3.9 \pm 0.5$ & $3.8 \pm 0.4$ & 1.8 & 0.2 & \\
\hline Periostal circumference (mm) & $87 \pm 5$ & $86 \pm 6$ & NS & $86 \pm 5$ & $86 \pm 5$ & -0.5 & 0.6 & \\
\hline Endosteal circumference $(\mathrm{mm})$ & $63 \pm 6$ & $61 \pm 6$ & NS & $62 \pm 7$ & $62 \pm 5$ & -1.4 & 0.6 & \\
\hline
\end{tabular}

Baseline comparison: all variables were adjusted for height. The baseline comparison (third column) is adjusted for height, the $P$ value for the group (control women or trans man) was not significant (NS). The comparison over time (last column) is performed by an ANOVA for repeated measurements with group (trans men or control women), visit (baseline or 12 months) and height as independents: $P$ value for visit $\times$ group, $* P<0.05$.

In our previous study, the observed bone phenotype in trans men under treatment was likely driven by changes in body composition, but the direct effects of testosterone on bone, in particular trabecular bone (6), and bone metabolism in trans men could not be ruled out (9). Using a multivariate statistical modeling, differences in both trabecular and cortical vBMD between trans men on longterm testosterone therapy and control women remained significant after adjusting for grip strength (9).

Secondly, testosterone can also act indirectly through estrogen aromatization. The effect of estrogen in male bone, especially bone geometry.

Our study has several limitations. Owing to the rarity of the condition, the sample size is small with implications for statistical power. Also, some trans men already used progestagens before the start of the study. The lower baseline LH at baseline is possibly due to the use of progestagens, but bone turnover and bone parameters at baseline were similar compared with those who did not used this treatment. Further, trans men were significantly shorter than control women and female Belgian standards (mean height for Belgian women: $166.6 \mathrm{~cm}$ ) (46). This difference has been previously reported, though its origin and significance are unknown (47). All tests on bone and body composition were, however, adjusted for height and yielded similar results as that of the unadjusted tests. Furthermore, although areal and volumetric bone changes can be detected during a 12-month follow-up $(48,49)$, the follow-up period might have been too short to detect bone geometry changes. Long-term follow-up is ongoing. The strengths of our study are the design and methods. Furthermore, we lack information on nutritional calcium intake, which may be relevant in the interpretation of the bone data (50). Trans men also smoked more and had lower vitamin D levels, which may be detrimental for bone (51). Bone parameters at baseline were comparable with control women. Cross-sex hormonal treatment in trans men provides a unique opportunity to observe the differential effects of sex steroids on genetically female bone. We use a prospective controlled design, which has, to our knowledge, not been reported in trans persons allowing the differentiation of changes due to aging or treatment. LCMS/MS was used for the determination of sex steroids, which has the required the sensitivity for assay of low ranges of $\mathrm{E}_{2}$, as found in trans men on testosterone therapy (16).

\section{Conclusion}

One year of testosterone treatment induced a higher muscle mass and lower fat mass in trans men, as well as higher bone turnover and modest increases in trabecular vBMD and aBMD. This may reflect the anabolic effects of testosterone on the female bone metabolism, possibly mediated by the higher strain on bone exerted by the androgen-induced increase in muscle mass.

\section{Declaration of interest}

The authors declare that there is no conflict of interest that could be perceived as prejudicing the impartiality of the research reported. 
Funding

This work was supported in part by Grant G.0867.11 from the Research Foundation Flanders. Eva Van Caenegem, Sara Vandewalle, and Katrien Wierckx are holders of a PhD fellowship from respectively the Research Foundation Flanders (Eva Van Caenegem and Sara Vandewalle) and Ghent University (Katrien Wierckx). This research support from Bayer and from the European Society for Sexual Medicine (Grant for Preclinical and Clinical Research 2012).

\section{Acknowledgements}

The authors are indebted to Griet De Cuypere, MD, PhD; Gunter Heylens, $\mathrm{MD}, \mathrm{PhD}$; Els Elaut, MSc; Birgit Van Hoorde, MSc; Steven Weyers, MD, PhD; Piet Hoebeke, MD, PhD; Stan Monstrey, MD, PhD for referral of participants; and to Jens Jacobeit, MD (MVZ Praxis im Chilehaus, Hamburg, Germany) and Mick van Trotsenburg, MD (Vrije Universiteit, Amsterdam, The Netherlands) for their contribution in the development of the ENIGI endocrinological protocol. They thank all volunteers who participated as study subjects. They also thank Veronique Van den Bossche and Kathelyne Mertens for their excellent technical assistance.

\section{References}

1 Riggs BL, Khosla S \& Melton LJ III. A unitary model for involutional osteoporosis: estrogen deficiency causes both type I and type II osteoporosis in postmenopausal women and contributes to bone loss in aging men. Journal of Bone and Mineral Research 199813 763-773. (doi:10.1359/jbmr.1998.13.5.763)

2 Khosla S, Melton LJ \& Riggs BL. The unitary model for estrogen deficiency and the pathogenesis of osteoporosis: is a revision needed? Journal of Bone and Mineral Research 201126 441-451. (doi:10.1002/jbmr.262)

3 Khosla S, Melton LJ III, Achenbach SJ, Oberg AL, Riggs BL \& Melton LJ. Hormonal and biochemical determinants of trabecular microstructure at the ultradistal radius in women and men. Journal of Clinical Endocrinology and Metabolism 200691 885-891. (doi:10.1210/jc.2005-2065)

4 Kirmani S, Christen D, van Lenthe GH, Fischer PR, Bouxsein ML, McCready LK, Melton LJ III, Riggs BL, Amin S, Müller R et al. Bone structure at the distal radius during adolescent growth. Journal of Bone and Mineral Research 200924 1033-1042. (doi:10.1359/jbmr.081255)

5 Vandewalle S, Taes Y, Fiers T, Toye K, Van Caenegem E, Roggen I, De Schepper J \& Kaufman JM. Associations of sex steroids with bone maturation, bone mineral density, bone geometry and body composition: a cross-sectional study in healthy male adolescents. Journal of Clinical Endocrinology and Metabolism 201499 E1272-E1282. (doi:10.1210/jc.2013-3887)

6 Vanderschueren D, Venken K, Ophoff J, Bouillon R \& Boonen S. Clinical review: Sex steroids and the periosteum - reconsidering the roles of androgens and estrogens in periosteal expansion. Journal of Clinical Endocrinology and Metabolism 200691 378-382. (doi:10.1210/jc. 2005-1766)

7 Szulc P \& Seeman E. Bone fragility: failure of periosteal apposition to compensate for increased endocortical resorption in postmenopausal women. Journal of Bone and Mineral Research 200621 1856-1863. (doi:10.1359/jbmr.060904)

8 Coleman E, Bockting W, Botzer M, Cohen-Kettenis P, DeCuypere G, Feldman J, Fraser L, Green J, Knudson G, Meyer WJ et al. Standards of care for the health of transsexual, transgender, and gender-nonconforming people, version 7. International Journal of Transgenderism 2012 13 165-232. (doi:10.1080/15532739.2011.700873)

9 Van Caenegem E, Wierckx K, Taes Y, Dedecker D, Van de Peer F, Toye K, Kaufman JM \& T'Sjoen G. Bone mass, bone geometry, and body composition in female-to-male transsexual persons after long-term cross-sex hormonal therapy. Journal of Clinical Endocrinology and Metabolism 201297 2503-2511. (doi:10.1210/jc.2012-1187)

10 Elbers JM, Asscheman H, Seidell JC \& Gooren LJ. Effects of sex steroid hormones on regional fat depots as assessed by magnetic resonance imaging in transsexuals. American Journal of Physiology 1999276 E317-E325.

11 Haraldsen IR, Haug E, Falch J, Egeland T \& Opjordsmoen S. Cross-sex pattern of bone mineral density in early onset gender identity disorder. Hormones and Behavior 200752 334-343. (doi:10.1016/j.yhbeh.2007. 05.012)

12 Mueller A, Haeberle L, Zollver H, Claassen T, Kronawitter D, Oppelt PG, Cupisti S, Beckmann MW \& Dittrich R. Effects of intramuscular testosterone undecanoate on body composition and bone mineral density in female-to-male transsexuals. Journal of Sexual Medicine 20107 3190-3198. (doi:10.1111/j.1743-6109.2010.01912.x)

13 Meriggiola MC, Armillotta F, Costantino A, Altieri P, Saad F, Kalhorn T, Perrone AM, Ghi T, Pelusi C \& Pelusi G. Effects of testosterone undecanoate administered alone or in combination with letrozole or dutasteride in female to male transsexuals. Journal of Sexual Medicine 20085 2442-2453. (doi:10.1111/j.1743-6109.2008.00909.x)

14 Kreukels BP, Haraldsen IR, De Cuypere G, Richter-Appelt H, Gijs L \& Cohen-Kettenis PT. A European network for the investigation of gender incongruence: the ENIGI initiative. European Psychiatry 201027 445-450. (doi:10.1016/j.eurpsy.2010.04.009)

15 Baecke JA, Burema J \& Frijters JE. A short questionnaire for the measurement of habitual physical activity in epidemiological studies. American Journal of Clinical Nutrition 198236 936-942.

16 Fiers T, Casetta B, Bernaert B, Vandersypt E, Debock M \& Kaufman J-M. Development of a highly sensitive method for the quantification of estrone and estradiol in serum by liquid chromatography tandem mass spectrometry without derivatization. Journal of Chromatography. B, Analytical Technologies in the Biomedical and Life Sciences 2012 893-894 57-62. (doi:10.1016/j.jchromb.2012.02.034)

17 Lapauw BM, Taes Y, Bogaert V, Vanbillemont G, Goemaere S, Zmierczak HG, De Bacquer D \& Kaufman JM. Serum estradiol and not testosterone influences volumetric bone mineral density and modulates the impact of physical activity on bone size at the age of peak bone mass - a study in healthy male siblings. Osteoporosis International 200924 1075-1085.

18 Herbst KL \& Bhasin S. Testosterone action on skeletal muscle. Current Opinion in Clinical Nutrition and Metabolic Care 20047 271-277. (doi:10.1097/00075197-200405000-00006)

19 Van Kesteren P, Lips P, Gooren LJ, Asscheman H \& Megens J. Long-term follow-up of bone mineral density and bone metabolism in transsexuals treated with cross-sex hormones. Clinical Endocrinology 199848 347-354.

20 Ruetsche AG, Kneubuehl R, Birkhaeuser MH \& Lippuner K. Cortical and trabecular bone mineral density in transsexuals after long-term cross-sex hormonal treatment: a cross-sectional study. Osteoporosis International 200516 791-798. (doi:10.1007/s00198-004-1754-7)

21 Turner A, Chen TC, Barber TW, Malabanan AO, Holick MF \& Tangpricha $\mathrm{V}$. Testosterone increases bone mineral density in female-to-male transsexuals: a case series of 15 subjects. Clinical Endocrinology 200461 560-566. (doi:10.1111/j.1365-2265.2004. 02125.x)

22 Goh HH \& Ratnam SS. Effects of hormone deficiency, androgen therapy and calcium supplementation on bone mineral density in female transsexuals. Maturitas 199726 45-52. (doi:10.1016/S0378-5122 (96)01073-0)

23 Wierckx K, Mueller S, Weyers S, Van Caenegem E, Roef G, Heylens G \& T'Sjoen G. Long-term evaluation of cross-sex hormone treatment in transsexual persons. Journal of Sexual Medicine 20129 2641-2651. (doi:10.1111/j.1743-6109.2012.02876.x)

24 Lips P, van Kesteren PJ, Asscheman H \& Gooren LJ. The effect of androgen treatment on bone metabolism in female-to-male 
transsexuals. Journal of Bone and Mineral Research 199611 1769-1773. (doi:10.1002/jbmr.5650111121)

25 Frost HM. Bone's mechanostat: a 2003 update. Anatomical Record. Part A, Discoveries in Molecular, Cellular, and Evolutionary Biology 2003275 1081-1101. (doi:10.1002/ar.a.10119)

26 Bass SL, Saxon L, Daly RM, Turner CH, Robling AG, Seeman E \& Stuckey S. The effect of mechanical loading on the size and shape of bone in pre-, peri-, and postpubertal girls: a study in tennis players. Journal of Bone and Mineral Research 200217 2274-2280. (doi:10.1359/ jbmr.2002.17.12.2274)

27 Kelley GA, Kelley KS \& Kohrt WM. Exercise and bone mineral density in premenopausal women: a meta-analysis of randomized controlled trials. International Journal of Endocrinology 20132013741639. (doi:10.1155/2013/741639)

28 Adami S, Gatti D, Viapiana O, Fiore CE, Nuti R, Luisetto G, Ponte M, Rossini M \& BONTURNO Study Group. Physical activity and bone turnover markers: a cross-sectional and a longitudinal study. Calcified Tissue International 200883 388-392. (doi:10.1007/s00223-008-9184-8)

29 Douchi T, Oki T, Yamasaki H, Kuwahata R, Nakae M \& Nagata Y. Relationship of androgens to muscle size and bone mineral density in women with polycystic ovary syndrome. Obstetrics and Gynecology 2001 98 445-449. (doi:10.1016/S0029-7844(01)01450-8)

30 Buchanan JR, Hospodar P, Myers C, Leuenberger P \& Demers LM. Effect of excess endogenous androgens on bone density in young women. Journal of Clinical Endocrinology and Metabolism 198867 937-943. (doi:10.1210/jcem-67-5-937)

31 Bechtold S, Dalla Pozza R, Putzker S, Roeb J, Buckel M, Weissenbacher C $\&$ Schmidt $\mathrm{H}$. Effect of antiandrogen treatment on bone density and bone geometry in adolescents with polycystic ovary syndrome. Journal of Pediatric and Adolescent Gynecology 201225 175-180. (doi:10.1016/j.jpag.2011.11.010)

32 Dagogo-Jack S, Al-Ali N \& Qurttom M. Augmentation of bone mineral density in hirsute women. Journal of Clinical Endocrinology and Metabolism 199782 2821-2825.

33 Glintborg D, Andersen M, Hagen C \& Hermann AP. Higher bone mineral density in Caucasian, hirsute patients of reproductive age. Positive correlation of testosterone levels with bone mineral density in hirsutism. Clinical Endocrinology 200562 683-691. (doi:10.1111/j.13652265.2005.02280.x)

34 Good C, Tulchinsky M, Mauger D, Demers LM \& Legro RS. Bone mineral density and body composition in lean women with polycystic ovary syndrome. Fertility and Sterility 199972 21-25. (doi:10.1016/ S0015-0282(99)00203-4)

35 Davis SR, McCloud P, Strauss BJ \& Burger H. Testosterone enhances estradiol's effects on postmenopausal bone density and sexuality. Maturitas 199561 17-26. (doi:10.1016/j.maturitas.2008.09.006)

36 Miller KK, Biller BM, Beauregard C, Lipman JG, Jones J, Schoenfeld D, Sherman JC, Swearingen B, Loeffler J \& Klibanski A. Effects of testosterone replacement in androgen-deficient women with hypopituitarism: a randomized, double-blind, placebo-controlled study. Journal of Clinical Endocrinology and Metabolism 200691 1683-1690. (doi:10.1210/jc.2005-2596)

37 Miller BE, De Souza MJ, Slade K \& Luciano AA. Sublingual administration of micronized estradiol and progesterone, with and without micronized testosterone: effect on biochemical markers of bone metabolism and bone mineral density. Menopause 20007 318-326. (doi:10.1097/00042192-200007050-00006)

38 Watts NB, Notelovitz M, Timmons MC, Addison WA, Wiita B \& Downey LJ. Comparison of oral estrogens and estrogens plus androgen on bone mineral density, menopausal symptoms, and lipid-lipoprotein profiles in surgical menopause. Obstetrics and Gynecology 199585 529-537. (doi:10.1016/0029-7844(94)00448-M)

39 Edwards MH, Gregson CL, Patel HP, Jameson KA, Harvey NC, Sayer AA, Dennison EM \& Cooper C. Muscle size, strength, and physical performance and their associations with bone structure in the Hertfordshire Cohort Study. Journal of Bone and Mineral Research 2013 28 2295-2304. (doi:10.1002/jbmr.1972)

40 Kaji H, Kosaka R, Yamauchi M, Kuno K, Chihara K \& Sugimoto T. Effects of age, grip strength and smoking on forearm volumetric bone mineral density and bone geometry by peripheral quantitative computed tomography: comparisons between female and male. Endocrine Journal 200552 659-666. (doi:10.1507/endocri.52.659)

41 Lebrasseur NK, Achenbach SJ, Melton LJ, Amin S \& Khosla S. Skeletal muscle mass is associated with bone geometry and microstructure and serum insulin-like growth factor binding protein-2 levels in adult women and men. Journal of Bone and Mineral Research 201227 2159-2169. (doi:10.1002/jbmr.1666)

42 Macdonald HM, Nishiyama KK, Kang J, Hanley DA \& Boyd SK. Age-related patterns of trabecular and cortical bone loss differ between sexes and skeletal sites: a population-based HR-pQCT study. Journal of Bone and Mineral Research 201126 50-62. (doi:10.1002/jbmr.171)

43 Bailey JM \& Zucker KJ. Childhood sex-typed behavior and sexual orientation: a conceptual analysis and quantitative review. Developmental Psychology 199531 43-55. (doi:10.1037/0012-1649.31.1.43)

44 Neu CM, Rauch F, Manz F, Schoenau E \& Schoenau E. Modeling of cross-sectional bone size, mass and geometry at the proximal radius: a study of normal bone development using peripheral quantitative computed tomography. Osteoporosis International 200112 538-547. (doi:10.1007/s001980170074)

45 Lorentzon M, Swanson C, Andersson N, Mellstrom D, Ohlsson C \& Mellström D. Free testosterone is a positive, whereas free estradiol is a negative, predictor of cortical bone size in young Swedish men: the GOOD study. Journal of Bone and Mineral Research 200520 1334-1341. (doi:10.1359/JBMR.050404)

46 Roelants M, Hauspie R \& Hoppenbrouwers K. References for growth and pubertal development from birth to 21 years in Flanders, Belgium. Annals of Human Biology 200936 680-694. (doi:10.3109/ 03014460903049074)

47 Bosinski H, Schröder I, Peter M, Arndt R, Wille R \& Sippell WG. Anthropometrical measurements and androgen levels in males, females, and hormonally untreated female-to-male transsexuals. Archives of Sexual Behavior 199726 143-157. (doi:10.1023/ A:1024506427497)

48 Isidori AM, Giannetta E, Greco EA, Gianfrilli D, Bonifacio V, Isidori A, Lenzi A \& Fabbri A. Effects of testosterone on body composition, bone metabolism and serum lipid profile in middle-aged men: a metaanalysis. Clinical Endocrinology 200563 280-293. (doi:10.1111/j.13652265.2005.02339.x)

49 Misra M, Katzman D, Miller KK, Mendes N, Snelgrove D, Russell M, Goldstein MA, Ebrahimi S, Clauss L, Weigel T et al. Physiologic estrogen replacement increases bone density in adolescent girls with anorexia nervosa. Journal of Bone and Mineral Research 201126 2430-2438. (doi:10.1002/jbmr.447)

50 Heaney RP. Dairy and bone health. Journal of the American College of Nutrition 200928 (Suppl 1) 82S-90S. (doi:10.1080/07315724.2009. 10719808)

51 Kanis JA, Johnell O, Oden A, Johansson H, De Laet C, Eisman JA, Fujiwara S, Kroger H, McCloskey EV, Mellstrom D et al. Smoking and fracture risk: a meta-analysis. Osteoporosis International 200516 155-162. (doi:10.1007/s00198-004-1640-3)

\section{Received 14 July 2014}

Revised version received 4 November 2014

Accepted 18 November 2014 